\title{
Out-of-office blood pressure: from measurement to control
}

This article was published in the following Dove Press journal:

Integrated Blood Pressure Control

8 May 2012

Number of times this article has been viewed

\author{
Jean-Philippe Baguet ${ }^{1,2}$ \\ 'Department of Cardiology, \\ University Hospital, ${ }^{2}$ Bioclinic \\ Radiopharmaceutics Laboratory, \\ INSERM UI039, Joseph Fourier \\ University, Grenoble, France
}

Correspondence: Jean-Philippe Baguet Clinique de Cardiologie, $\mathrm{CHU}$ de Grenoble, BP 217 38043, Grenoble, Cedex 09, France

Tel +33476768480

Fax +33476765559

Email jpbaguet@chu-grenoble.fr

\begin{abstract}
Hypertension is an important risk factor for the development of cardiovascular disease, and is a major cause of morbidity and mortality worldwide. Traditionally, hypertension diagnosis and treatment and clinical evaluations of antihypertensive efficacy have been based on office blood pressure (BP) measurements; however, there is increasing evidence that office measures may provide inadequate or misleading estimates of a patient's true BP status and level of cardiovascular risk. The introduction, and endorsement by treatment guidelines, of 24-hour ambulatory BP monitoring and self (or home) BP monitoring has facilitated more reliable and reproducible estimations of true BP, including the identification of white-coat and masked hypertension, and evaluation of BP variability. In addition, ambulatory BP monitoring enables accurate assessment of treatment effectiveness over 24 hours and both ambulatory and self BP monitoring may lead to better tailoring of therapy according to BP profile and concomitant disease. This review describes the clinical benefits and limitations of out-of-office assessments and their applications for effective management of hypertension and attainment of BP control.
\end{abstract}

Keywords: ambulatory, ABPM, SBPM, blood pressure measurement, hypertension

\section{Introduction}

The association of high blood pressure (BP) and the occurrence of vascular events such as stroke and coronary artery disease is well known. ${ }^{1,2}$ The majority of epidemiological studies establishing a relationship between cardiovascular (CV) and cerebrovascular morbidity and mortality and BP have been based on clinical BP measurement. In addition, most therapeutic trials of hypertension have used lowering clinical BP as the primary endpoint, as a surrogate for reduced CV or renal disease. However, the occurrence of hypertension-related target organ damage and CV or cerebrovascular events have been shown to be more correlated with 24-hour ambulatory and self-measured BP values than to office BP measurements. ${ }^{3-7}$ This is mainly due to the high variability of BP from one cycle to the next and during the nycthemeral period.

Ambulatory BP monitoring (ABPM) and self (or home) BP monitoring (SBPM) techniques were developed to provide a more standardized and reliable estimation of true BP and CV risk. The diagnostic and prognostic value of both methods is increasingly recognized by treatment guidelines; for example, the recent updates to the United Kingdom National Institute of Clinical Excellence guidelines include a recommendation of $\mathrm{ABPM}$ or SBPM for diagnosis of hypertension in patients with clinic BP of $>140 / 90 \mathrm{mmHg}$ and for evaluation of treatment efficacy. ${ }^{8}$ 
Here, the clinical benefits and limitations of each method and their applications for the management of hypertension are reviewed.

\section{4-hour ABPM}

Initially reserved for research purposes, ABPM has become a widely used clinical tool. It is the noninvasive method of BP measurement that provides the most detailed information for a given patient over a 24-hour period, including circadian fluctuations and differences between daytime and nighttime BP (Figure 1). ABPM is more reproducible than office measurements, ${ }^{9}$ and despite being more restrictive for patients than self-measuring devices, tolerance of ABPM is good and has no detrimental effect on sleep quality. ${ }^{10}$

To be effective, ABPM devices must be independently validated according to international protocols. ${ }^{11-13}$ Different sampling intervals can be used, although it is best not to exceed 20-30 minutes to avoid incorrect estimates of 24-hour, daytime, or nighttime BP values. ${ }^{14}$ Based on cross-sectional population studies, the upper normality limit for BP (ie, the value corresponding to an office $\mathrm{BP}$ of $>140 / 90 \mathrm{mmHg}$ ) approximately corresponds to mean 24-hour BP values of $125-130 / 80 \mathrm{mmHg}$ and daytime BP values of $130-135 / 85 \mathrm{mmHg}$. ${ }^{8,15,16}$

\section{ABPM for identifying white-coat and masked hypertension}

Advantages of ABPM include identification of patients with white-coat or masked hypertension. The former is characterized by a persistently high office BP but normal ambulatory BP. The prevalence of white-coat hypertension is high, presenting in about $15 \%$ of the general population and accounting for a noticeable proportion (one-third or more) of individuals in whom hypertension is diagnosed. ${ }^{15}$ White-coat hypertension appears to be more common in women, the elderly, and patients with mild hypertension. ${ }^{17}$ These patients would normally receive antihypertensive treatment on the basis of office BP measurement, thus identification is important as patients with white-coat hypertension may respond differently to antihypertensive drugs and may develop more side-effects from treatment. ${ }^{18}$ Most data indicate white-coat hypertension represents a lower $\mathrm{CV}$ risk than sustained hypertension (ie, found by both office and ambulatory recordings); however, conflicting evidence regarding the prevalence of target organ damage and susceptibility to future hypertension has led to uncertainty as to whether white-coat hypertension represents a truly innocent phenomenon. ${ }^{19-22}$ Clinical trials are needed to ascertain whether treatment of patients with white-coat hypertension reduces adverse clinical events.

Masked hypertension (also known as reverse white-coat hypertension, white-coat normotension, or isolated ambulatory hypertension) is defined as normal BP values in the office but elevated BP outside the office (using ABPM or SBPM). Its prevalence varies according to the studied population, but is approximately $15 \% .{ }^{22}$ Cross-sectional studies have shown that masked hypertension is associated with increased left ventricular mass, carotid intimal medial thickness, and arterial stiffness. ${ }^{23-25}$ Epidemiological prospective studies suggest that masked hypertension is an independent and strong predictor of CV morbidity and mortality. $22,26-30$

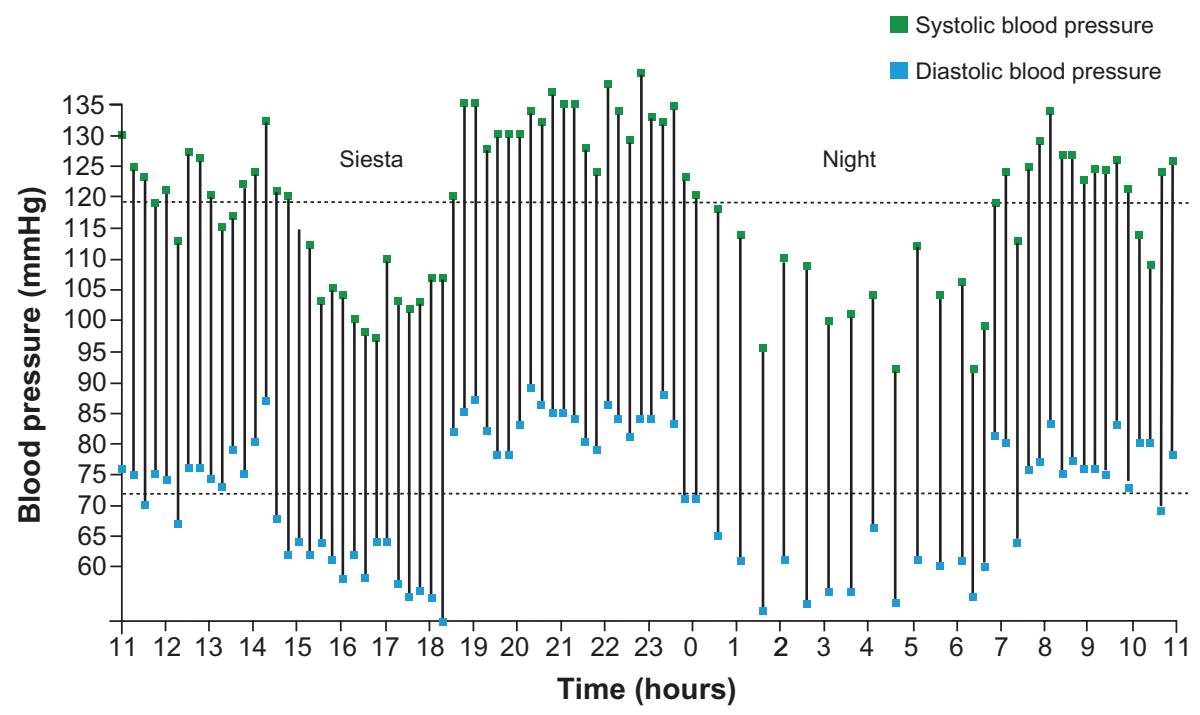

Figure I Twenty-four-hour ambulatory blood pressure measurement showing a fall in blood pressure during a siesta and at night. 
Factors that can raise ambulatory BP increase the likelihood of having masked hypertension. ${ }^{31}$

\section{ABPM and $C V$ outcomes}

Several studies have demonstrated the prognostic benefit of ABPM, with evidence that 24-hour daytime or nighttime average BP values correlate with subclinical organ damage more closely than office values. ${ }^{7,32-34}$ The Ohasama study - the first study to address the prognostic value of ABPM - reported a greater association between ambulatory $\mathrm{BP}$ and $\mathrm{CV}$ mortality than office BP. ${ }^{33}$ Clement et al showed that for the same clinical systolic BP, CV prognosis was worsened (incidence of CV events multiplied by two to three) when 24-hour systolic BP was $\geq 135 \mathrm{mmHg}{ }^{7}$ In the SYST-EUR (Systolic Hypertension in Europe) study, ambulatory but not clinical BP was shown to predict CV mortality during follow-up; higher 24-hour BP was associated with total, cardiac, and cerebrovascular events in untreated hypertensives. ${ }^{34}$

\section{ABPM for evaluating pharmacological treatment of hypertension}

To reduce $\mathrm{CV}$ risk of patients with hypertension, antihypertensive agents should provide effective, sustained, and smooth BP reduction throughout the 24-hour dosing period. ${ }^{35-37}$ ABPM has drastically improved the ability to assess the efficacy of antihypertensive drugs in both clinical trials and medical practice. ${ }^{38-42}$ Greater reproducibility, lack of placebo effect, and absence of an alerting-dependent BP response make ABPM the ideal tool to quantify the antihypertensive effect of new drugs in clinical trials, as well as drug combinations or nonpharmacological measures. ${ }^{39}$ It also makes it possible to compare the ability of different drugs or doses to provide smooth and consistent reductions in BP using indices such as trough-to-peak ratio and smoothness index..$^{37,43}$

\section{ABPM for personalizing treatment according to BP profile Morning BP}

There is a steep rise in BP between sleeping and waking. This has clinical importance since a morning peak is related to an increased incidence of coronary events and stroke, notably among elderly patients. ${ }^{44,45}$ It is therefore important to ensure antihypertensive therapies provide coverage throughout the 24-hour dosing period, thereby blunting the early morning surge in BP. ${ }^{46}$ ABPM allows assessment of antihypertensive efficacy during windows of the 24-hour cycle, including the early morning period.

\section{Nighttime BP and dipping status}

Nighttime BP is considered to be a better predictor of $\mathrm{CV}$ risk and mortality than daytime BP.4,34,47,48 The normal circadian rhythm of BP includes a nocturnal decrease of $15 \%-25 \%$ in $\mathrm{BP}$ compared to daytime values. ${ }^{46} \mathrm{ABPM}$ is beneficial in determining dipper status, notably the deleterious effect of nondipping whereby patients with hypertension demonstrate a nocturnal BP fall of $<10 \%$ compared with daytime BP. Loss of nocturnal decline in BP has been associated with increased risk of cardiac, renal, and vascular target organ damage compared with normotensive patients. ${ }^{48-50}$ Verdecchia et al noted a risk of CV events 2.5 times higher in nondipper hypertensives, ${ }^{49}$ whilst Kario et al showed that nondipping and extreme dipping (nocturnal BP fall of $>20 \%$ ) were associated with an increased risk of cerebrovascular damage (ie, lacunae and periventricular white matter hyperintensity). ${ }^{50}$ Studies have demonstrated that evening administration of long-acting antihypertensives results in greater reduction of nighttime BP than morning administration, without loss of 24-hour efficacy. ${ }^{51-53}$ For example, the Spanish MAPEC (Ambulatory Blood Pressure Monitoring for Prediction of Cardiovascular Events) prospective study demonstrated that bedtime administration of hypertension therapies exerted significantly better BP control and CV risk reduction than conventional morning administration. ${ }^{51}$ Subjects taking medication at bedtime showed significantly lower mean sleeptime BP and a significantly reduced prevalence of nondipping (34\% versus $62 \% ; P<0.001$ ) than subjects taking medication upon awakening..$^{51}$ In addition, evening dosing was associated with a higher prevalence of controlled ambulatory BP $(62 \%$ versus $53 \% ; P<0.001)$ and a significantly lower risk of total $\mathrm{CV}$ disease events. ${ }^{51}$ Timing treatment administration to reflect the circadian variation of the renin-angiotensin system is therefore an effective means of optimizing treatment of patients with essential hypertension.

\section{BP variability}

ABPM provides a powerful tool for establishing and analyzing BP variability, which is increased in patients with hypertension and associated with target organ damage and CV risk. ${ }^{25,54,55}$ Long-acting antihypertensives that provide consistent and durable BP reduction may be beneficial in reducing BP variability; ${ }^{56}$ however, accurate analysis of variability is still in the research phase and this parameter cannot yet be used to classify patient risk and assess the efficacy of antihypertensive treatment. 


\section{ABPM for specific clinical conditions} Obstructive sleep apnea (OSA)

OSA and hypertension are linked in a dose-response fashion. ${ }^{57}$ Many mechanisms are responsible for OSA-related hypertension, notably sympathetic hyperactivity. ${ }^{58}$ Although more than half of apneic patients are hypertensive, it is well established that hypertension is largely underdiagnosed in OSA patients. ${ }^{59}$ Hypertension must be systematically looked for and treated in apneic subjects, particularly if it is predominantly nocturnal, diastolic, refractory, or linked to a nondipper profile. ${ }^{60} \mathrm{ABPM}$ enables detection of hypertension in OSA patients, ${ }^{60}$ and is useful for evaluating the efficacy of antihypertensive drugs. For example, a recent study of untreated hypertensive OSA patients demonstrated that valsartan induced a four-fold greater decrease in mean 24-hour BP than continuous positive airway pressure. ${ }^{61}$ However, additional studies are needed to establish the effect of antihypertensive treatment on clinical outcomes in OSA patients.

\section{Diabetes and metabolic syndrome}

Diabetes and metabolic syndrome are recognized as $\mathrm{CV}$ risk factors. ${ }^{15}$ Patients with hypertension have up to three times higher risk of developing diabetes than normotensives, ${ }^{62}$ and the prevalence of nondipping is high. ${ }^{63-65}$ The coexistence of diabetes and hypertension has been linked to a substantial increased risk of renal and other organ damage, leading to a higher incidence of stroke and CV events. ${ }^{15} \mathrm{ABPM}$ enables early detection of hypertension in diabetic and metabolic syndrome patients, facilitating early treatment and risk reduction. In type 1 diabetic patients, ABPM with position analysis may be used to determine different patterns in relation to the disease duration and the presence of microangiopathy. ${ }^{66}$

\section{Heart failure}

In most cases of systolic left ventricular dysfunction, BP is low. This is not without consequence as a systolic BP lower than $105 \mathrm{mmHg}$ over 24 hours may be an excess mortality factor. ${ }^{67}$ The prevalence of nondipping in heart failure patients is high (approximately $80 \%$ ), ${ }^{68}$ necessitating detection and monitoring by ABPM and better treatment of hemodynamic parameters.

\section{SBPM}

SBPM is becoming increasingly popular among patients and gaining greater acceptance among physicians as a valuable adjunct to office monitoring. The clinical and prognostic value of SBPM is recognized by treatment guidelines, ${ }^{8,15,69}$ and the technique is recommended by the National Institute of Clinical Excellence as an alternative to ABPM for confirming diagnosis of hypertension. ${ }^{8}$ SBPM is useful in diagnosing essential hypertension, white-coat hypertension, and refractory hypertension. In addition, it can be used to evaluate BP control and detect orthostatic hypotension in treated hypertensives. The technique also has the benefit of making patients more aware of their disease and CV risk, and may facilitate compliance with treatment. ${ }^{70}$

The prognostic value of SBPM on the occurrence of $\mathrm{CV}$ events has been well demonstrated. ${ }^{4}$ The SHEAF (Selfmeasurement of BP at Home in the Elderly: Assessment and Follow-up) study, which included nearly 5000 hypertensive patients aged over 60 , showed that the risk of $\mathrm{CV}$ events was doubled if the SBPM remained abnormal under treatment, whereas the office BP was normalized. ${ }^{26}$ The study also demonstrated that the CV morbimortality of treated hypertensive subjects suffering from masked hypertension was identical to that of treated but uncontrolled hypertensive subjects (both office measurement and SBPM), ie, triple that of subjects with normal BP. ${ }^{26}$

SBPM has the weakness of not capturing nocturnal BP and not allowing comparison of BP profiles between day and night, or analysis of the early morning BP surge. However, the technique can be used to capture daytime ambulatory BP and a greater number of readings can be taken than office monitoring, and in a more realistic setting, thus avoiding white-coat hypertension. ${ }^{70}$ Being less restrictive than ABPM, SBPM is better accepted by patients ${ }^{71,72}$ and is more accessible to physicians.

For the technique to be effective, SBPM must follow a strict procedure (eg, sitting position, several minutes rest, correct cuff size) using validated tools, with priority to semiautomatic and brachial devices. ${ }^{15,69}$ Measurements must be made in the morning (before drug intake) and evening for several days in a row. When several measurements are made over several minutes, the results of the first one must not be taken into account because they are often higher than the others. ${ }^{69}$ Normal values of BP measured in SBPM are a systolic BP lower than $135 \mathrm{mmHg}$ and a diastolic BP lower than $85 \mathrm{mmHg} .{ }^{15}$

\section{Treatment of hypertension and evaluation of BP control}

The 2009 reappraisal of European guidelines on hypertension management recommends lowering office systolic/diastolic BP to values within the range $130-139 / 80-85 \mathrm{mmHg}$, and possibly close to lower values in this range in all 


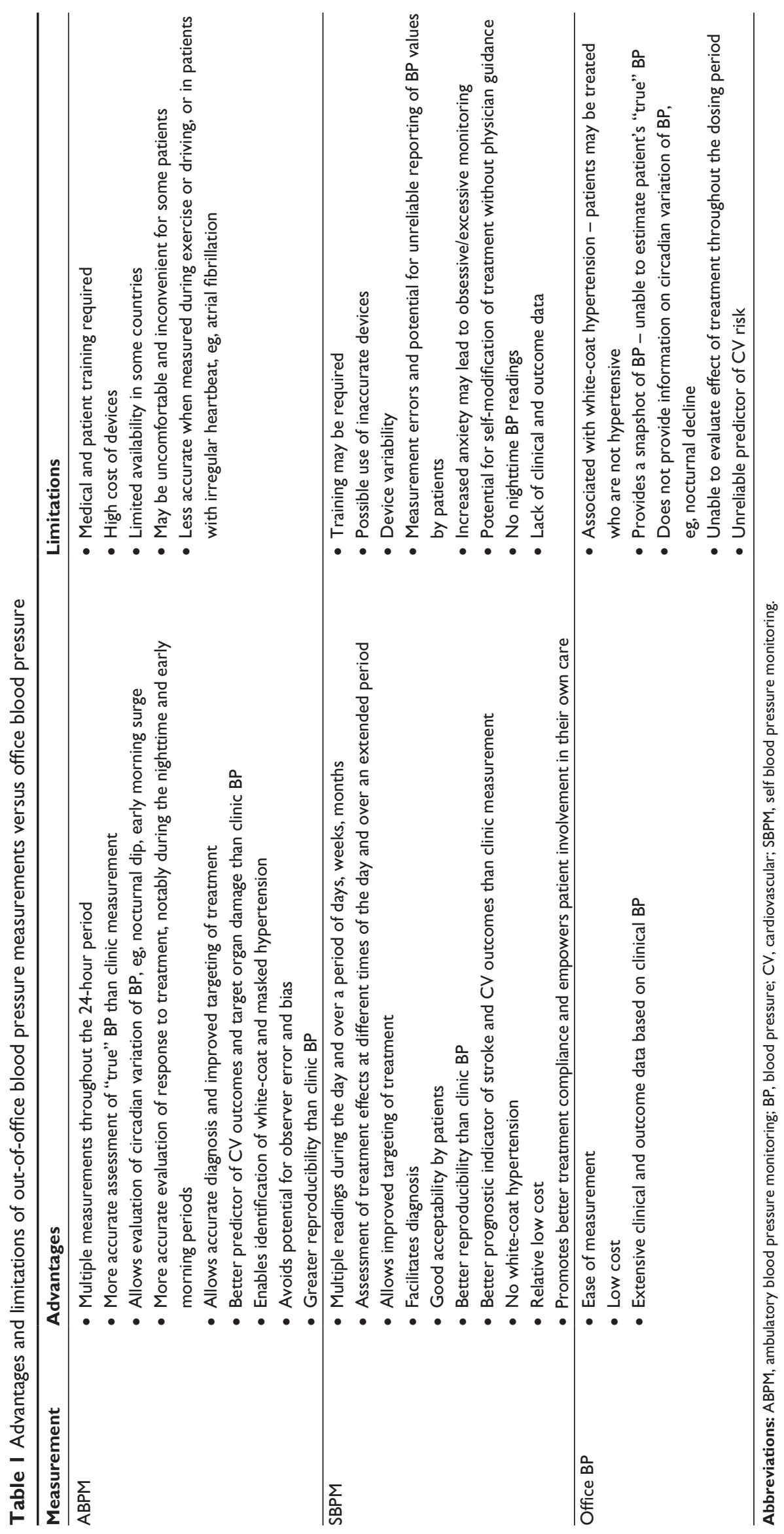


hypertensive patients. ${ }^{73}$ In the vast majority of patients, effective BP control can only be achieved by combining at least two antihypertensive drugs. ${ }^{73}$ As recommended by the European guidelines, drugs that exert their antihypertensive effect over 24 hours with a once-a-day administration should be preferred because a simple treatment schedule promotes compliance. $^{15}$

As discussed earlier in this review, ABPM and SBPM are valuable methods for verifying the BP lowering efficacy of antihypertensives over 24 hours. The effect of antihypertensives is known to be greater on clinical BP than ambulatory $\mathrm{BP},{ }^{39}$ and the proportion of patients achieving satisfactory BP control may be different when BP is measured in the clinic or by ambulatory monitoring. ${ }^{26,74,75}$ For example, a study of 103 treated patients demonstrated that a large number of patients deemed to be controlled by office BP did not have adequate BP control based on ABPM. ${ }^{74}$ The SHEAF trial has added to the complexity of hypertension control by showing that office readings were inaccurate in $22 \%$ of treated hypertensive patients: $13 \%$ had uncontrolled clinic BP but controlled SBPM, and 9\% had controlled clinic BP but uncontrolled SBPM. ${ }^{26}$ The shortfalls of clinic BP were also demonstrated in the AASK (African American Study of Kidney Disease and Hypertension) trial, in which the majority of subjects with controlled clinic BP were shown to have abnormal BP profiles including nondipping and/or reverse dipping, elevated nighttime BP, and masked hypertension. ${ }^{76}$ These studies urge caution when interpreting clinic BP measures and support a more systematic adoption of ABPM and SBPM within clinical practice.

\section{Out-of-office versus clinic measurements: advantages and limitations}

As discussed above, there is now convincing evidence that ABPM and SBPM provide more reliable BP measurements and are better predictors of $\mathrm{CV}$ complications and target organ damage than office measures. However, differences exist in their clinical benefits and limitations (Table 1). Cost and availability are major deciding factors for choice of BP measurement method; for example, the use of ABPM in routine practice is often confined to high-risk patients or subjects with resistant hypertension due to the cost of devices and the need for personnel who are trained to use the devices and interpret the data. On the contrary, the increasing availability of low-cost, accurate SBPM devices no longer limits their use in clinical practice. Whilst the implementation of ABPM within practice can be challenging, substantial benefits can be realized in terms of better targeting of treatment and reduced healthcare costs. ${ }^{77}$

\section{Conclusion}

ABPM has broadened the horizons of hypertension research. The endorsement of ABPM by treatment guidelines and increasing awareness among physicians regarding the benefits of this measure over traditional office measurements may lead to more accurate diagnosis, more appropriately targeted treatment, and improved clinical outcomes. This method of measuring BP gives more information than SBPM, but these two techniques are not mutually exclusive and both provide greater diagnostic and prognostic benefits than clinic BP measurements. Data from ABPM and SBPM enable accurate assessment of treatment effectiveness and thus may help tailor therapy for optimal BP management. With BP control rates remaining suboptimal, increased use of ABPM and SBPM for assessment of 24-hour control is warranted, especially in high-risk patients. Questions remain regarding the impact of ABPM and SBPM on clinical outcomes as the majority of existing data are from observational studies. Further clinical trials are needed, using ABPM and/or SBPM to evaluate primary outcomes of treatment efficacy and CV risk reduction. Additional research is also needed to obtain information about issues that remain unclear, such as the clinical importance of white-coat hypertension and ambulatory BP variability.

\section{Disclosure}

The author reports no conflicts of interest in this work. Takeda Pharmaceuticals Europe Ltd has provided an educational grant to support the production of this manuscript, including provision of editorial support by Virgo HEALTH. The final version of the manuscript was reviewed by Takeda Pharmaceuticals Europe Ltd for medical accuracy only; Takeda Pharmaceuticals Europe Ltd had no involvement in the article's content.

\section{References}

1. The Systolic Hypertension in the Elderly Program Cooperative Research Group. Implications of the systolic hypertension in the elderly program. Hypertension. 1993;21(3):335-343.

2. Turnbull F. Effects of different blood-pressure-lowering regimens on major cardiovascular events: results of prospectively-designed overviews of randomised trials. Lancet. 2003;362(9395):1527-1535.

3. Staessen JA, Asmar R, De Buyzere M, et al. Task Force II: blood pressure measurement and cardiovascular outcome. Blood Press Monit. 2001;6(6):355-370.

4. Sega R, Facchetti R, Bombelli M, et al. Prognostic value of ambulatory and home blood pressures compared with office blood pressure in the general population: follow-up results from the Pressioni Arteriose Monitorate e Loro Associazioni (PAMELA) study. Circulation. 2005; 111(14):1777-1783. 
5. Hansen TW, Jeppesen J, Rasmussen S, Ibsen H, Torp-Pedersen C. Ambulatory blood pressure and mortality: a population-based study. Hypertension. 2005;45(4):499-504.

6. Fagard RH, Van Den Broeke C, De CP. Prognostic significance of blood pressure measured in the office, at home and during ambulatory monitoring in older patients in general practice. J Hum Hypertens. 2005;19(10):801-807.

7. Clement DL, De Buyzere ML, De Bacquer DA, et al. Prognostic value of ambulatory blood-pressure recordings in patients with treated hypertension. $N$ Engl J Med. 2003;348(24):2407-2415.

8. National Institute for Health and Clinical Excellence. Hypertension: clinical management of primary hypertension in adults. August 2011. Available from: http://www.nice.org.uk/nicemedia/live/13561/56008/56008.pdf. Accessed April 6, 2012.

9. Chaves H, Campello de Souza FM, Krieger EM. The reproducibility of dipping status: beyond the cutoff points. Blood Press Monit. 2005; 10(4):201-205.

10. Tropeano AI, Roudot-Thoraval F, Badoual T, et al. Different effects of ambulatory blood pressure monitoring on subjective and objective sleep quality. Blood Press Monit. 2006;11(6):315-320.

11. O'Brien E, Asmar R, Beilin L, et al. European Society of Hypertension recommendations for conventional, ambulatory and home blood pressure measurement. J Hypertens. 2003;21(5):821-848.

12. O'Brien E, Petrie J, Littler W, et al. The British Hypertension Society protocol for the evaluation of automated and semi-automated blood pressure measuring devices with special reference to ambulatory systems. J Hypertens. 1990;8(7):607-619.

13. Association for the Advancement of Medical Instrumentation. American National Standard for Electronic or Automated Sphymomanometers. Arlington, VA: Association for the Advancement of Medical Instrumentation; 1983.

14. Di Rienzo M, Grassi G, Pedotti A, Mancia G. Continuous vs intermittent blood pressure measurements in estimating 24-hour average blood pressure. Hypertension. 1983;5(2):264-269.

15. Mancia G, De Backer G, Dominiczak A, et al. 2007 guidelines for the management of arterial hypertension: The Task Force for the Management of Arterial Hypertension of the European Society of Hypertension (ESH) and of the European Society of Cardiology (ESC). Eur Heart J. 2007;28(12):1462-1536.

16. Mancia G, Sega R, Bravi C, et al. Ambulatory blood pressure normality: results from the PAMELA study. J Hypertens. 1995;13(12 Pt 1): 1377-1390.

17. Chrysant SG. Treatment of white coat hypertension. Curr Hypertens Rep. 2000;2(4):412-417.

18. O'Brien E. The value of 24-h blood pressure monitoring to assess the efficacy of antihypertensive drug treatment. Hot Topics Hypertens. 2011; $4(12): 7-23$.

19. Kotsis V, Stabouli S, Toumanidis S, et al. Target organ damage in "white coat hypertension" and "masked hypertension." Am J Hypertens. 2008;21(4):393-399.

20. Glen SK, Elliott HL, Curzio JL, Lees KR, Reid JL. White-coat hypertension as a cause of cardiovascular dysfunction. Lancet. 1996;348(9028): 654-657.

21. Verdecchia P, Schillaci G, Borgioni C, Ciucci A, Porcellati C. Whitecoat hypertension: not guilty when correctly defined. Blood Press Monit. 1998;3(3):147-152.

22. Mancia G, Facchetti R, Bombelli M, Grassi G, Sega R. Long-term risk of mortality associated with selective and combined elevation in office, home, and ambulatory blood pressure. Hypertension. 2006;47(5):846-853.

23. Sega R, Trocino G, Lanzarotti A, et al. Alterations of cardiac structure in patients with isolated office, ambulatory, or home hypertension: data from the general population (Pressione Arteriose Monitorate ELoro Associazioni [PAMELA] Study). Circulation. 2001;104(12):1385-1392.

24. Ormezzano O, Baguet JP, Francois P, Quesada JL, Pierre H, Mallion JM. Is there any real target organ damage associated with white-coat normotension? Clin Auton Res. 2004;14(3):160-166.
25. Pierdomenico SD, Lapenna D, Bucci A, et al. Blood pressure variability and prognosis in uncomplicated mild hypertension. Am Heart $J$. 2005;149(5):934-938.

26. Bobrie G, Chatellier G, Genes N, et al. Cardiovascular prognosis of "masked hypertension" detected by blood pressure self-measurement in elderly treated hypertensive patients. JAMA. 2004;291(11): $1342-1349$.

27. Bjorklund K, Lind L, Zethelius B, Berglund L, Lithell H. Prognostic significance of 24-h ambulatory blood pressure characteristics for cardiovascular morbidity in a population of elderly men. J Hypertens. 2004;22(9):1691-1697.

28. Ohkubo T, Kikuya M, Metoki H, et al. Prognosis of "masked" hypertension and "white-coat" hypertension detected by 24-h ambulatory blood pressure monitoring 10-year follow-up from the Ohasama study. $\mathrm{JAm}$ Coll Cardiol. 2005;46(3):508-515.

29. Fagard RH, Cornelissen VA. Incidence of cardiovascular events in whitecoat, masked and sustained hypertension versus true normotension: a meta-analysis. J Hypertens. 2007;25(11):2193-2198.

30. Mancia G, Bombelli M, Facchetti R, et al. Long-term risk of sustained hypertension in white-coat or masked hypertension. Hypertension. 2009;54(2):226-232.

31. Mallion JM, Clerson P, Bobrie G, Genes N, Vaisse B, Chatellier G. Predictive factors for masked hypertension within a population of controlled hypertensives. J Hypertens. 2006;24(12):2365-2370.

32. Mancia G, Parati G. Ambulatory blood pressure monitoring and organ damage. Hypertension. 2000;36(5):894-900.

33. Ohkubo T, Imai Y, Tsuji I, et al. Relation between nocturnal decline in blood pressure and mortality. The Ohasama Study. Am J Hypertens. 1997;10(11):1201-1207.

34. Staessen JA, Thijs L, Fagard R, et al; Systolic Hypertension in Europe Trial Investigators. Predicting cardiovascular risk using conventional vs ambulatory blood pressure in older patients with systolic hypertension. JAMA. 1999;282(6):539-546.

35. Mancia G, Parati G. Importance of smooth and sustained blood pressure control in preventing cardiovascular morbidity and mortality. Blood Press Suppl. 2001;3:26-32.

36. Meredith PA. The importance of sustained blood pressure control. J Cardiovasc Pharmacol. 2000;35 Suppl 3:S7-S11.

37. Neutel JM. The importance of 24-h blood pressure control. Blood Press Monit. 2001;6(1):9-16.

38. Coats AJ, Radaelli A, Clark SJ, Conway J, Sleight P. The influence of ambulatory blood pressure monitoring on the design and interpretation of trials in hypertension. $J$ Hypertens. 1992;10(4):385-391.

39. Mancia G, Parati G. Office compared with ambulatory blood pressure in assessing response to antihypertensive treatment: a meta-analysis. J Hypertens. 2004;22(3):435-445.

40. Bakris GL, Sica D, Weber M, et al. The comparative effects of azilsartan medoxomil and olmesartan on ambulatory and clinic blood pressure. J Clin Hypertens (Greenwich). 2011;13(2):81-88.

41. Sica D, White WB, Weber MA, et al. Comparison of the novel angiotensin II receptor blocker azilsartan medoxomil vs valsartan by ambulatory blood pressure monitoring. J Clin Hypertens (Greenwich). 2011;13(7):467-472.

42. White WB, Weber MA, Sica D, et al. Effects of the angiotensin receptor blocker azilsartan medoxomil versus olmesartan and valsartan on ambulatory and clinic blood pressure in patients with stages 1 and 2 hypertension. Hypertension. 2011;57(3):413-420.

43. Parati G, Omboni S, Rizzoni D, Agabiti-Rosei E, Mancia G. The smoothness index: a new, reproducible and clinically relevant measure of the homogeneity of the blood pressure reduction with treatment for hypertension. J Hypertens. 1998;16(11):1685-1691.

44. Li Y, Thijs L, Hansen TW, et al. Prognostic value of the morning blood pressure surge in 5645 subjects from 8 populations. Hypertension. 2010;55(4):1040-1048.

45. Kario K. Morning surge in blood pressure and cardiovascular risk: evidence and perspectives. Hypertension. 2010;56(5): $765-773$. 
46. White WB. Importance of blood pressure control over a 24-hour period. J Manag Care Pharm. 2007;13(8 Suppl B):34-39.

47. Fagard RH, Celis H, Thijs L, et al. Daytime and nighttime blood pressure as predictors of death and cause-specific cardiovascular events in hypertension. Hypertension. 2008;51(1):55-61.

48. de la Sierra A, Segura J, Gorostidi M, Banegas JR, de la Cruz JJ, Ruilope LM. Diurnal blood pressure variation, risk categories and antihypertensive treatment. Hypertens Res. 2010;33(8):767-771.

49. Verdecchia P, Schillaci G, Borgioni C, et al. Altered circadian blood pressure profile and prognosis. Blood Press Monit. 1997;2(6):347-352.

50. Kario K, Matsuo T, Kobayashi H, Imiya M, Matsuo M, Shimada K. Nocturnal fall of blood pressure and silent cerebrovascular damage in elderly hypertensive patients. Advanced silent cerebrovascular damage in extreme dippers. Hypertension. 1996;27(1):130-135.

51. Hermida RC, Ayala DE, Mojon A, Fernandez JR. Influence of circadian time of hypertension treatment on cardiovascular risk: results of the MAPEC study. Chronobiol Int. 2010;27(8):1629-1651.

52. Hermida RC, Ayala DE, Fernandez JR, Portaluppi F, Fabbian F, Smolensky MH. Circadian rhythms in blood pressure regulation and optimization of hypertension treatment with ACE inhibitor and ARB medications. Am J Hypertens. 2011;24(4):383-391.

53. Takeda A, Toda T, Fujii T, Matsui N. Bedtime administration of longacting antihypertensive drugs restores normal nocturnal blood pressure fall in nondippers with essential hypertension. Clin Exp Nephrol. 2009;13(5):467-472.

54. Parati G, Faini A, Valentini M. Blood pressure variability: its measurement and significance in hypertension. Curr Hypertens Rep. 2006;8(3): 199-204.

55. Sega R, Corrao G, Bombelli M, et al. Blood pressure variability and organ damage in a general population: results from the PAMELA study (Pressioni Arteriose Monitorate E Loro Associazioni). Hypertension. 2002;39(2 Pt 2):710-714.

56. Oparil S. Hypertension in 2010: new challenges in blood pressure goals and assessment. Nat Rev Cardiol. 2011;8(2):73-75.

57. Peppard PE, Young T, Palta M, Skatrud J. Prospective study of the association between sleep-disordered breathing and hypertension. N Engl J Med. 2000;342(19):1378-1384.

58. Somers VK, Dyken ME, Clary MP, Abboud FM. Sympathetic neural mechanisms in obstructive sleep apnea. $J$ Clin Invest. 1995;96(4):1897-1904.

59. Grote L, Hedner J, Peter JH. Mean blood pressure, pulse pressure and grade of hypertension in untreated hypertensive patients with sleeprelated breathing disorder. J Hypertens. 2001;19(4):683-690.

60. Baguet JP, Hammer L, Levy P, et al. Night-time and diastolic hypertension are common and underestimated conditions in newly diagnosed apnoeic patients. $J$ Hypertens. 2005;23(3):521-527.

61. Pepin JL, Tamisier R, Barone-Rochette G, Launois SH, Levy P, Baguet JP. Comparison of continuous positive airway pressure and valsartan in hypertensive patients with sleep apnea. Am J Respir Crit Care Med. 2010;182(7):954-960.

62. Grossman E, Messerli FH. Management of blood pressure in patients with diabetes. Am J Hypertens. 2011;24(8):863-875.
63. Borel AL, Benhamou PY, Baguet JP, et al. Short sleep duration is associated with a blood pressure nondipping pattern in type 1 diabetes: the DIAPASOM study. Diabetes Care. 2009;32(9):1713-1715.

64. Gorostidi M, de la Sierra A, Gonzalez-Albarran O, et al. Abnormalities in ambulatory blood pressure monitoring in hypertensive patients with diabetes. Hypertens Res. 2011;34(11):1185-1189.

65. Hermida RC, Chayan L, Ayala DE, et al. Association of metabolic syndrome and blood pressure nondipping profile in untreated hypertension. Am J Hypertens. 2009;22(3):307-313.

66. Benhamou PY, Mouret S, Quesada JL, et al. Variations of ambulatory blood pressure with position in patients with type 1 diabetes: influence of disease duration and microangiopathy in a pilot study. Diabetes Care. 2001;24(9):1624-1628.

67. Canesin MF, Giorgi D, Oliveira MT Jr, et al. Ambulatory blood pressure monitoring of patients with heart failure. A new prognosis marker. Arq Bras Cardiol. 2002;78(1):83-89.

68. Mallion JM, Neuder Y, Ormezzano O, Rochette GB, Salvat M, Baguet JP. Study of nycthemeral variations in blood pressure in patients with heart failure. Blood Press Monit. 2008;13(3):163-165.

69. Parati G, Stergiou GS, Asmar R, et al. European Society of Hypertension practice guidelines for home blood pressure monitoring. J Hum Hypertens. 2010;24(12):779-785.

70. Celis H, Den Hond E, Staessen JA. Self-measurement of blood pressure at home in the management of hypertension. Clin Med Res. 2005;3(1):19-26.

71. Little P, Barnett J, Barnsley L, Marjoram J, Fitzgerald-Barron A, Mant D. Comparison of acceptability of and preferences for different methods of measuring blood pressure in primary care. $B M J$. 2002;325(7358):258-259.

72. Stergiou GS, Kollias A, Nasothimiou EG. Home blood pressure monitoring: application in clinical practice. Hipertension y Riesgo Vascular. 2011;28(4):149-153. Spanish.

73. Mancia G, Laurent S, Agabiti-Rosei E, et al. Reappraisal of European guidelines on hypertension management: a European Society of Hypertension Task Force document. J Hypertens. 2009;27(11):2121-2158.

74. Wilson MD, Barron JJ, Johnson KA, et al. Determination of ambulatory blood pressure control in treated patients with controlled office blood pressures. Blood Press Monit. 2000;5(5-6):263-269.

75. Felix-Redondo FJ, Fernandez-Berges D, Espinosa-Garcia J, et al. Level of blood pressure control in a hypertensive population when measurements are performed outside the clinical setting. Cardiol $J$. 2009;16(1):57-67.

76. Pogue V, Rahman M, Lipkowitz M, et al. Disparate estimates of hypertension control from ambulatory and clinic blood pressure measurements in hypertensive kidney disease. Hypertension. 2009;53(1):20-27.

77. Lovibond K, Jowett S, Barton P, et al. Cost-effectiveness of options for the diagnosis of high blood pressure in primary care: a modelling study. Lancet. 2011;378(9798):1219-1230.
Integrated Blood Pressure Control

\section{Publish your work in this journal}

Integrated Blood Pressure Control is an international, peer-reviewed open-access journal focusing on the integrated approach to managing hypertension and risk reduction. Treating the patient and comorbidities together with diet and lifestyle modification and optimizing healthcare resources through a multidisciplinary team approach constitute key

\section{Dovepress}

features of the journal. This journal is indexed on American Chemical Society's Chemical Abstracts Service (CAS). The manuscript management system is completely online and includes a very quick and fair peerreview system, which is all easy to use. Visit http://www.dovepress.com/ testimonials.php to read real quotes from published authors. 